\title{
Correlation between functional and radiological outcome after surgical stabilization of volar Barton fracture with plating: a comparative study
}

\author{
Vikram Goud ${ }^{1}$, Manoj Kanamarlapudi ${ }^{2 *}$
}

\begin{abstract}
${ }^{1}$ Department of Orthopaedics, Kamineni Hospital, LB Nagar, Hyderabad, Telangana, India
${ }^{2}$ Department of Orthopaedics, Employees State Insurance Corporation Medical College and Hospital, Sanathnagar, Hyderabad, Telangana, India
\end{abstract}

Received: 13 April 2020

Revised: 29 April 2020

Accepted: 30 April 2020

\section{*Correspondence:}

Dr. Manoj Kanamarlapudi,

E-mail: drmanoj456@gmail.com

Copyright: (C) the author(s), publisher and licensee Medip Academy. This is an open-access article distributed under the terms of the Creative Commons Attribution Non-Commercial License, which permits unrestricted non-commercial use, distribution, and reproduction in any medium, provided the original work is properly cited.

\section{ABSTRACT}

Background: The objective of the study was to evaluate the functional and radiological outcomes after open reduction with internal fixation of volar Barton's fracture of the wrist and compare their outcomes.

Methods: Total of 30 cases of volar Barton fractures were operated by open reduction and internal fixation with plating. Mean follow up period was 6 months. Patients were assessed both radiological and functional outcome and compare between the two outcomes.

Results: All fractures were healed in a mean period of 7 weeks (range 6-9 weeks). The mean disabilities of the arm, shoulder and hand (DASH) score was 13.21 points (range: 10.3 to 30), thus confirming the patient's good functional capacity. The higher the DASH score was (i.e. the worse the functional result), the smaller were the flexion $(p=0.01)$, pronation $(\mathrm{p}=0.03)$, supination $(\mathrm{p}<0.0001)$ and radial deviation $(\mathrm{p}=0.005)$ of the wrist that underwent the surgical procedure after the fracture of the distal extremity of the radius. The radiological results were evaluated by modified Lidstrom criteria.

Conclusions: The radiographic results did not influence the DASH score. There was no statistical relationship between the DASH score and the radial height or the volar tilt or the radial tilt of the distal extremity of the operated radius.

Keywords: Volar Barton fracture, Plating, Functional outcome, Radiological outcome

\section{INTRODUCTION}

Barton's fractures, named after the American surgeon John Rhea Barton, who first described it in 1838 , is a fracture of the distal end of the radius which involves the articular surface. ${ }^{1}$ This fracture can be either an anterior marginal (volar Barton) or posterior (dorsal Barton) marginal fracture. These fractures may be either due to low energy or high energy injuries but high energy injuries are more frequent cause of volar Barton's fracture. ${ }^{2-5}$ Volar Barton's fractures are different from other distal radius fractures in that there is an associated radio carpal dislocation. Conservative treatment is usually unsuccessful in these fractures unlike other distal radius fractures which have good functional outcome with conservative treatment. These fractures are associated with complications like loss of reduction, malunion, nonunion, deformity, subluxation and instability ${ }^{6-8}$ Various surgical treatment modalities are reported in literature. Open reduction and internal fixation (osteosynthesis) with a volar plate system have shown good results. The advantages of this system are good reduction of articular surface and achieves immediate stability of joint leading to early mobilization of wrist and potential reduction of wrist and finger stiffness and reduction of early onset of wrist osteoarthritis. ${ }^{9-11}$ The aim of this study is to correlate between functional and 
radiological outcome after surgical stabilization of volar Barton fracture with plating.

\section{METHODS}

This study was conducted in the Department of Orthopaedics, Kamineni Hospitals, Hyderabad from May 2015 to January 2017. It was a prospective comparative study. Total of 30 cases of volar Barton fractures were operated by open reduction and internal fixation (ORIF) with plating. The mean age of the 20 men and 10 women was 30 years (range: 20-65 years). The mechanism of injury was road traffic accident (high velocity) in 18 cases and fall on outstretched hand in 12 cases. The Barton's fractures were classified according to a comprehensive classification system based on radiographic and operative findings. ${ }^{12}$ All 30 cases were type-B3 fractures. In terms of fracture subtype, 8 cases were B3.1 (fracture characterised by a small volar fragment and an intact sigmoid notch), 10 were B3.2 fractures (a large volar fragment that included the sigmoid notch), and 12 were B3.3 fractures (comminution of the volar fragment).

Table 1: Sarmiento radiological score (modified Lidstrom criteria).

\begin{tabular}{|llll|} 
Outcome & $\begin{array}{l}\text { Loss of } \\
\text { palmar tilt }\end{array}$ & $\begin{array}{l}\text { Radial } \\
\text { shortening }\end{array}$ & $\begin{array}{l}\text { Loss of radial } \\
\text { deviation }\end{array}$ \\
\hline Excellent & $<0^{\circ}$ & $<3 \mathrm{~mm}$ & $<4^{\circ}$ \\
\hline Good & $1-10^{\circ}$ & $3-6 \mathrm{~mm}$ & $5-9^{\circ}$ \\
\hline Fair & $11-14^{\circ}$ & $7-11 \mathrm{~mm}$ & $10-14^{\circ}$ \\
\hline Poor & $>15^{\circ}$ & $>12 \mathrm{~mm}$ & $>15^{\circ}$ \\
\hline
\end{tabular}

\section{Inclusion criteria}

Adults over 18 yrs of age, both male and female with volar Barton fracture with or without other associated injuries, patients medically fit for surgery, patients willing for surgical treatment and have given informed written consent were included.
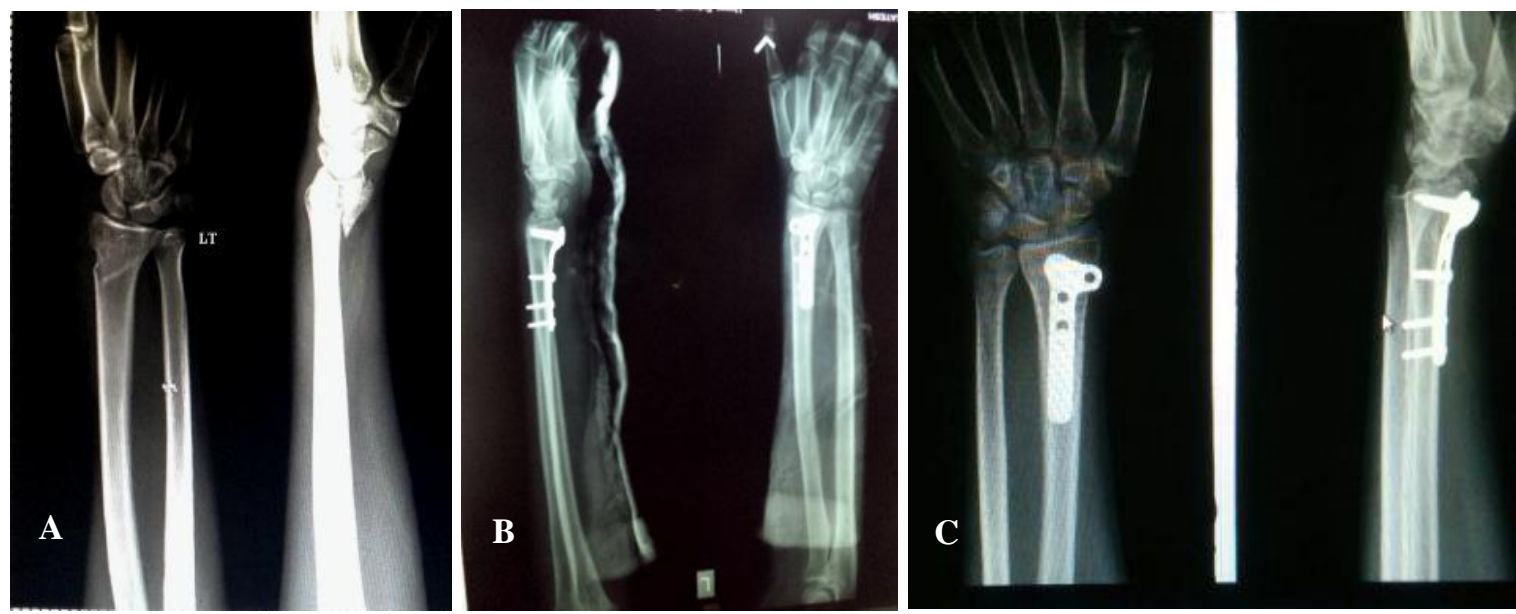

Figure 1: Preoperative radiograph of a 28-year-old male with a B3.2 volar Barton fracture, (B) postoperative
Open fractures requiring soft tissue reconstruction, intra articular fractures with dorsal comminution, pathological fractures, patients with neurovascular injury, patient not willing for consent were excluded.

\section{Surgical technique}

General anesthesia with interscalene block was used for all patients. A pneumatic tourniquet was used in all cases in order to provide bloodless field during surgery. The fracture site was exposed through the distal part of the modified Henry approach. ${ }^{13}$ Open reduction of all major fragments was performed, focusing on restoring articular congruity. Kirschner wires were used to temporarily stabilise the position of fracture fragments. Definitive fixation was done with a $3.5 \mathrm{~mm}$ Ellis T-plate (B3.1 and B3.2) and variable angle locking plate for B3.3 fractures.

Post op dressing done on $2^{\text {nd }}$ day and suture removal done after 10 days from date of surgery. Finger range of motion exercises started immediately after surgery and active movement of wrist was started after 2 weeks of surgery. Post op radiographs were taken immediately, 3 weeks, 3 months and final evaluation at 6 months (Figure 1). At final evaluation the functional results were analysed using the protocol for dysfunctions of the arm, shoulder and hand (DASH) and radiological results were evaluated in accordance with the Sarmiento radiological score, modified Lidstrom anatomical-radiological classification for fractures of the distal extremity of the radius, as excellent, good, fair or poor (Table 1). ${ }^{14,15}$

The data were reported as the mean $\pm \mathrm{SD}$. The Spearman rho test was used to assess the variables. A " $p$ " value of $<0.05$ using a two-tailed test was taken as being of significance for all statistical tests. All data were analysed with a statistical software package (SPSS, version 19.0 for windows).

\footnotetext{
radiograph after ORIF with $\mathrm{T}$ plate, $(\mathrm{C})$ at 6 months follow up showing good union.
} 


\section{RESULTS}

Thirty cases of volar Barton's fracture were operated by ORIF. There were $20(66 \%)$ males and $10(34 \%)$ females. The mean age was 30 years (range: $20-65$ years). The mean follows up was 6 months. The right hand was involved in $18(60 \%)$ patients. The mechanism of injury was highenergy trauma (i.e. road traffic accident) in $17(51.6 \%)$ patients, fall in $10(33.3 \%)$ and $3(10 \%)$ patients had polytrauma.

All fractures were healed in a mean period of 7 weeks (range 6-9 weeks). There were no significant postoperative complications. The mean DASH score was 13.21 points (range: 10.3 to 30 ), thus confirming the patients' good functional capacity. The patients had greatest difficulty with regard to their ability to carry heavy objects (more than $5 \mathrm{~kg}$ ), perform activities that required an impact and doing heavy domestic tasks.
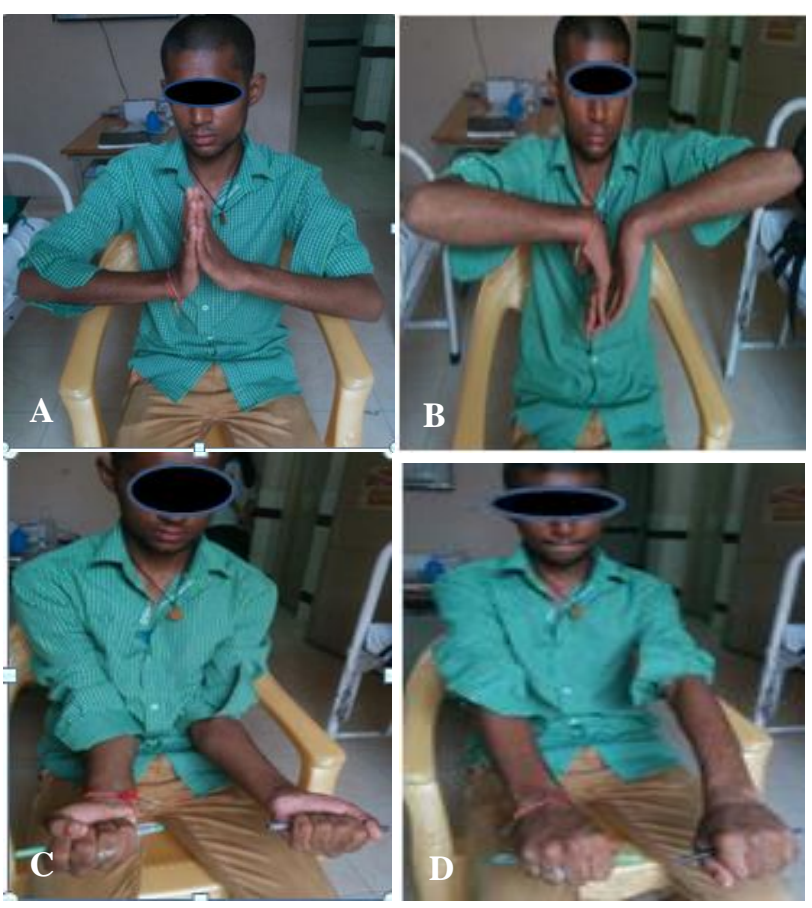

Figure 2 (A-D): Movements at follow up after 6 months showing full range of motion.
The following mean ranges of motion were documented: wrist flexion of $67^{\circ}$ (normal up to $80^{\circ}$ ), extension of $66^{\circ}$ (normal up to $70^{\circ}$ ), pronation of $65^{\circ}$ (normal up to $90^{\circ}$ ), supination of $66^{\circ}$ (normal up to $90^{\circ}$ ), ulnar displacement of $24^{\circ}$ (normal up to $45^{\circ}$ ) and radial displacement of $11^{\circ}$ (normal up to $15^{\circ}$ ) (Figure 2).

Table 2: Distribution of patients according to their demographic and clinical characteristics.

\begin{tabular}{|ll|}
\hline Variables & $\mathbf{N}(\%)$ \\
\hline Age distribution (in years) & $7(23.3)$ \\
\hline $20-30$ & $9(30.0)$ \\
\hline $31-40$ & $12(40.0)$ \\
\hline $41-50$ & $2(6.7)$ \\
\hline $51-60$ & $10(66.7)$ \\
\hline Gender distribution & $20(33.3)$ \\
\hline Females & \\
\hline Males & $18(60.0)$ \\
\hline Side involved & $12(40.0)$ \\
\hline Right & \\
\hline Left & $18(60.0)$ \\
\hline Mode of injury & $12(40.0)$ \\
\hline Road traffic accidents & \\
\hline Fall of height & $8(26.7)$ \\
\hline Type of fracture & $10(33.3)$ \\
\hline B3.1 & $12(40.0)$ \\
\hline B3.2 & \\
\hline B3.3 & $5(16.7)$ \\
\hline Union in weeks & $17(56.7)$ \\
\hline 12 & $8(26.7)$ \\
\hline 14 & \\
\hline 16 & $25(83.3)$ \\
\hline Complications & $3(10.0)$ \\
\hline Nil & $1(3.3)$ \\
\hline Stiffness & $1(3.3)$ \\
\hline Malunion & $5(16.6)$ \\
\hline EPL tendon irritation & $18(60)$ \\
\hline Lidstrom criteria & $7(23.4)$ \\
\hline Excellent & 0 \\
\hline Good & \\
\hline Fair & \\
\hline Poor & \\
\hline
\end{tabular}

Table 3: Hypothesis test summary (non parametric test) each variable is correlated with DASH scoring.

\begin{tabular}{|llll|}
\hline Null hypothesis & Test & Significance & Decision \\
\hline $\begin{array}{l}\text { The distribution of variable (radial height) normal } \\
\text { with mean } \mathbf{5 . 2 6} \text { and standard deviation } \mathbf{4 . 2 3 7}\end{array}$ & $\begin{array}{l}\text { One sample Kolmogorov } \\
- \text { Smirnov test }\end{array}$ & 0.158 & $\begin{array}{l}\text { Retain the null } \\
\text { hypothesis }\end{array}$ \\
\hline $\begin{array}{l}\text { The distribution of variable (volar tilt) normal with } \\
\text { mean 4.64 and standard deviation 1.449 }\end{array}$ & $\begin{array}{l}\text { One sample Kolmogorov } \\
- \text { Smirnov test }\end{array}$ & 0.200 & $\begin{array}{l}\text { Retain the null } \\
\text { hypothesis }\end{array}$ \\
\hline $\begin{array}{l}\text { The distribution of variable (radial tilt) normal } \\
\text { with mean } \mathbf{7 . 4 3} \text { and standard deviation } \mathbf{2 . 6 4 6}\end{array}$ & $\begin{array}{l}\text { One sample Kolmogorov } \\
- \text { Smirnov test }\end{array}$ & 0.200 & $\begin{array}{l}\text { Retain the null } \\
\text { hypothesis }\end{array}$ \\
\hline
\end{tabular}

The significance level is 0.05 . 
The radiological results were evaluated by modified Lidstrom criteria, we had rated as excellent in $5(16.6 \%)$ patients, as they had no or insignificant deformity, loss of palmar tilt $\geq 0^{\circ}$, shortening of $<3 \mathrm{~mm}$, loss of radial deviation $<4^{\circ}$ with no complications. $18(60 \%)$ patients had slight deformity, loss of palmar tilt of $1-10^{\circ}$, shortening of 3-6 mm, loss of radial deviation $5-9^{\circ}$, so the result was rated as good. 7 (23.4\%) patients had moderate deformity, loss of palmar tilt of $11-14^{\circ}$, shortening of 7-11 $\mathrm{mm}$, loss of radial deviation $10-14^{\circ}$ and the result was rated as fair.

Three patients (10\%) developed stiffness due to failure to compliance with postoperative physical therapy. One patient $(3.3 \%)$ had extensor pollicis longus tendon irritation due to long volar to dorsal screw and one patient (3.3\%) developed radiocarpal arthrosis due to malunion (Table 2).

\section{Correlation between clinical and radiographic results}

The functional and radiographic results were correlated by means of statistical analysis. Firstly, an analysis was performed between the DASH score and the documented range of motion of each of the patients in the study. It was observed that the flexion, pronation, supination and radial deviation were correlated with the DASH score, with statistical significance $(\mathrm{p}<0.05)$. The higher the DASH score was (i.e. the worse the functional result), the smaller were the flexion $(\mathrm{p}=0.01)$, pronation $(\mathrm{p}=0.03)$, supination $(p<0.0001)$ and radial deviation $(p=0.005)$ of the wrist that underwent the surgical procedure after the fracture of the distal extremity of the radius. Subsequently, an analysis was performed between the DASH score and the radiographic results obtained. The radiographic results did not influence the DASH score. There was no statistical relationship between the DASH score and the radial height or the volar tilt or the radial tilt of the distal extremity of the operated radius (Table 3).

\section{DISCUSSION}

Over the last decade, several studies have been directed towards clarifying which surgical treatment method would be best for fracture of the distal extremity of the radius. In this context, Osada et al, demonstrated that volar plates are well tolerated, allow early mobilization and provide good support for deforming muscle forces after the surgical reduction, even in intra-articular fracture. ${ }^{16}$

We did not observe any correlation between the radiographic outcome and the functional result. This ratifies the findings of Tsukazaki et al, i.e. that the severity of the initial displacement, the involvement of the radiocarpal or distal radioulnar joint and the presence of fracture of the styloid process of the ulna did not affect the functional result from treating the fracture of the distal extremity of the radius with a fixed-angle plate. $^{17}$
Fujii et al observed that there was no relationship between the functional result and reestablishment of the radiographic parameters of the distal extremity of the radius to the way they were before the fracture. ${ }^{18}$ Moreover, in the study by Jaremko et al patients undergoing conservative treatment for fractures of the distal extremity of the radius were evaluated and it was observed that there was no relationship between the functional results and reduction of the fracture to acceptable radiographic levels. ${ }^{19}$ Our data confirm the findings of Fujii et al and Jaremko et al, i.e. that the radiological values did not influence the range of motion. Thus, the final change in dorsal tilt of the radius seen on lateral-view radiographs, and the change in radial tilt and height seen on anteroposterior-view radiographs that were produced as routine postoperative check-ups on the patients in the study were inconclusive for affirming that there were any relationship with the range of motion of the wrist.

We found that the range of motion of the wrist joint, and particularly the flexion, pronation, supination and radial deviation were influenced by the DASH score result. There was an inversely proportional relationship between the range of motion of the wrist that underwent the surgical procedure and the DASH score, and this was statistically significant $(\mathrm{p}<0.05)$. We found that with greater flexion, pronation, supination and radial displacement of the wrist, we obtained a better functional result (lower numerical DASH score).

As observed in the study by Chung et al, open reduction and internal fixation enabled early mobilization and an earlier return to normal activities that with plaster-cast immobilization of the wrist for six weeks. ${ }^{20}$ Wakefield et al. also observed that carrying out exercises at home was a form of rehabilitation that was as good as having regular physiotherapy sessions after treatment of non-complicated fractures of the distal extremity of the radius. ${ }^{21}$

\section{CONCLUSION}

We conclude that, based on the functional results obtained by using the wrist rom and DASH scoring system, and radiological results obtained by using Sarmiento modification of Lidstrom criteria, treatment of distal radius volar Barton fracture by using volar plating technique showed good results even though radiological results are fair or poor. This study demonstrates that the subjective functional results are influenced by the range of motion, particularly volar and dorsal flexion, supination, pronation and radial deviation of the wrist after the surgical procedure, which shows early rehabilitation as key in such cases.

\author{
Funding: No funding sources \\ Conflict of interest: None declared \\ Ethical approval: The study was approved by the \\ institutional ethics committee
}




\section{REFERENCES}

1. Peltier LF. Eponymic fractures: John Rhea Barton and Barton's fractures. Surgery. 1953;34(5):960-70.

2. Slutsky DJ, Osterman AL. Fractures and injuries of the distal radius and carpus: thecutting edge. Saunders/Elsevier; 2009: 563.

3. Tang Z, Yang H, Chen K, Wang G, Zhu X, Qian Z. Therapeutic Effects of Volar Anatomical Plates Versus Locking Plates for Volar Barton's Fractures. Orthopedics. 2012;35(8):1198-203.

4. Aggarwal A. Open reduction and internal fixation of volar Barton's fractures: A prospective study. J Orthop Surg (Hong Kong). 2004;12(2):230-4.

5. Dai M-H, Wu C-C, Liu H-T, Wang I-C, Yu C-M, Wang K-C, et al. Treatment of volar Barton's fractures: comparison between two common surgical techniques. Chang Gung Med J. 2006;29(4):388-94.

6. Vasenius J. Operative Treatment of Distal Radius Fractures. Scand J Surg. 2008;97(4):290-6.

7. Bartl C, Stengel D, Bruckner T, Rossion I, Luntz S, Seiler C, et al. Open reduction and internal fixation versus casting for highly comminuted and intraarticular fractures of the distal radius (ORCHID): protocol for a randomized clinical multi-center trial. Trials. 2011;12:84

8. Twigt B, Bemelman M, Lansink K, Leenen L. Type $\mathrm{C}$ distal radial fractures treated withconventional AO plates: an easy and cost-saving solution in a locking plate era. Int Orthop.2013;37(3):483-8.

9. Jupiter JB, Fernandez DL, Toh CL, Fellman T, Ring D. Operative treatment of volar intra-articular fractures of the distal end of the radius. J Bone Joint Surg Am. 1996;78(12):1817-28.

10. Harness N, Ring D, Jupiter JB. Volar Barton's fractures with concomitant dorsal fracture in older patients. J Hand Surg Am. 2004;29(3):439-45.

11. Volar Barton's fractures with concomitant dorsal fracture in older patients. J Hand Surg Am. 2004;29(3):439-45.

12. Mehara AK, Rastogi S, Bhan S, Dave PK. Classification and treatment of volar Barton fractures. Injury. 1993;24(1):55-9.
13. Ilyas AM, Ilyas AM. Surgical approaches to the distal radius. Hand. 2011;6:8-17.

14. Wright TW, Horodyski M, Smith DW. Functional outcome of unstable distal radius fractures: ORIF with a volar fixed-angle tine plate versus external fixation. J Hand Surg Am. 2005;30(2):289-99.

15. Kwok IHY, Leung F, Yuen G. Assessing results after distal radius fracture treatment: a comparison of objective and subjective tools. Geriatr Orthop Surg Rehabil. 2011;2(4):155-60.

16. Osada D, Kamei S, Masuzaki K, Takai M, Kameda M, Tamai K. Prospective Study of Distal Radius Fractures Treated With a Volar Locking Plate System. J Hand Surg Am. 2008;33(5):691-700.

17. Tsukazaki T, Takagi K, Iwasaki K. Poor correlation between functional results andradiographic findings in Colles' fracture. J Hand Surg Br. 1993;18(5):58891.

18. Fujii K, Henmi T, Kanematsu Y, Mishiro T, Sakai T, Terai T. Fractures of the Distal End of Radius in Elderly Patients: A Comparative Study of Anatomical and Functional Results. J Orthop Surg. 2002;10(1):9-15.

19. Jaremko JL, Lambert RGW, Rowe BH, Johnson JA, Majumdar SR. Do radiographic indices of distal radius fracture reduction predict outcomes in older adults receiving conservative treatment Clin Radiol. 2007;62(1):65-72.

20. Chung KC, Watt AJ, Kotsis S V, Margaliot Z, Haase SC, Kim HM. Treatment of Unstable Distal Radial Fractures with the Volar Locking Plating System. J Bone Jt Surg. 2006;88(12):2687.

21. Wakefield AE, McQueen MM. The role of physiotherapy and clinical predictors of outcome after fracture of the distal radius. J Bone Joint Surg Br. 2000;82(7):972-6.

Cite this article as: Goud V, Kanamarlapudi M. Correlation between functional and radiological outcome after surgical stabilization of volar Barton fracture with plating: a comparative study. Int J Res Orthop 2020;6:666-70. 